\title{
Green Synthesis of Silver Nanoparticles from the Opuntia ficus-indica Fruit and Its Activity against Treated Wastewater Microorganisms
}

\author{
Mariana G. Muñoz-Carrillo $\mathbb{D}^{1},{ }^{1}$ Cristina Garcidueñas-Piña $\left(\mathbb{D},{ }^{1}\right.$ \\ Roberto C. Valerio-García ${ }^{D},{ }^{1}$ José L. Carrazco-Rosales $\mathbb{D}^{\mathbb{D}}{ }^{2}$ \\ and José F. Morales-Domínguez $\mathbb{D}^{1}$ \\ ${ }^{1}$ Department of Chemistry, Autonomous University of Aguascalientes, Aguascalientes 20131, Mexico \\ ${ }^{2}$ Department of Microbiology, Autonomous University of Aguascalientes, Aguascalientes 20131, Mexico
}

Correspondence should be addressed to José F. Morales-Domínguez; jfmoral@correo.uaa.mx

Received 27 May 2020; Revised 23 September 2020; Accepted 29 October 2020; Published 17 November 2020

Academic Editor: Bhanu P. S. Chauhan

Copyright (c) 2020 Mariana G. Muñoz-Carrillo et al. This is an open access article distributed under the Creative Commons Attribution License, which permits unrestricted use, distribution, and reproduction in any medium, provided the original work is properly cited.

\begin{abstract}
Wastewater can be reused after a treatment process and compliance with high quality standards that guarantee its safe use. The wastewater treatment plant of the Autonomous University of Aguascalientes (AUA), like others, uses primary, secondary, and tertiary processes. The tertiary process followed is chlorination and is used to eliminate microorganisms from the secondary process. Although water of acceptable quality is obtained with chlorine, there is evidence that toxic substances are generated when reacting with organic matter, so alternatives to the use of chlorination have been analyzed. In the present study, silver nanoparticles were synthesized from the aqueous extract of the Opuntia ficus indica fruit peel (OfAgNPs), by reducing a $2 \mathrm{mM}$ solution of $\mathrm{AgNO}_{3}$. OfAgNPs were characterized by UV-visible spectroscopy, scanning electron microscopy, energy-dispersive $\mathrm{X}$-ray spectroscopy, atomic absorption spectroscopy, and dynamic light scattering, in addition to his electrophoretic mobility. The OfAgNPs are spherical, with an average particle size distribution of $64.28 \pm 11.82 \mathrm{~nm}$, relatively stable at room temperature, negatively charged $(-25.1 \pm 0.03 \mathrm{mV})$, and composed of $61.29 \%$ silver. The activity of OfAgNPs was evaluated in water from the effluent of the AUA treatment plant, before and after chlorination, and inhibition of bacteria Escherichia coli var 1, Enterobacter aerogenes var 1, Citrobacter freudi var 2, atypical E. coli, and aerobic mesophilic microorganism was tested.
\end{abstract}

\section{Introduction}

Nanotechnology is the science of the design and production of materials at nanoscale $(1-100 \mathrm{~nm})$, also called nanomaterials, characterized by having different physical, chemical, and biological properties than those of larger scales [1]. Within these nanomaterials are nanoparticles (NPs), which measure less than $100 \mathrm{~nm}$ [2]. Silver NPs (AgNPs) have been employed in various important applications in human health such as antibacterial, antifungal, antiviral, and anticancer [3-6].

Different NPs synthesis methods have been developed in which its physicochemical properties depend directly, such as size, surface charge, agglomeration, degree of dilution, and elemental composition $[7,8]$. The synthesis of AgNPs based on chemical reduction is the most popular, simple, and high performance [9], where a metallic precursor (metallic salts) reacts with reducing agents such as sodium citrate, ascorbic acid, alcohol, and borohydride, which are toxic for the environment [10]. Furthermore, chemical synthesis processes can increase the toxicity of NPs due to its ability to absorb substances [10-12]. One of the alternatives is green synthesis in which chemical reducing agents and stabilizers are replaced by proteins, vitamins, alkaloids, carbohydrates, and antioxidants, which are obtained from living organisms such as bacteria, algae, fungi, yeasts, and plants [10-13]. The advantages of this technique are the following: (a) the 
reduction of costs during synthesis, (b) processes are simpler, and (c) the resulting product is compatible for pharmaceutical applications and for biomedical use $[10,11,14]$. Some of the plants that have been reported for green synthesis are Azadirachta indica [15], Boerhaavia diffusa [16], Malva parviflora [17], Olea chrysophylla, Lavandula dentata [18], Pelargonium beenides [19], among others.

On the other hand, wastewater is defined as water from discharges of urban, industrial, services, agricultural, livestock, and domestic uses, and it is defined as treated wastewater after it has undergone any or all of the physical, chemical, and biological processes that make it suitable for reuse [20], generally for domestic use and irrigation water. Through physical process, solid waste is separated from water; with biological process, for example, activated sludge, a consortium of microorganisms removes organic matter; and with the chemical process, the microorganisms present are eliminated, for example, by chlorination [21,22]. A disadvantage of the chlorination process is that when chlorine reacts in the environment, it generates by-products with genotoxic, mutagenic, and carcinogenic effect [23]. For this reason, alternatives to the use of chlorine in the tertiary process are being investigated.

An important parameter to determine the quality of treated wastewater is measuring the load of indicator bacteria. This allows to indirectly calculate the presence of pathogenic microorganisms. Direct detection of pathogenic microorganisms can be a difficult and expensive process, with long analysis and culture isolation times. Furthermore, with indicator bacteria, it is possible to evaluate different physical and chemical disinfection treatments [24, 25]. The most widely used indicator microorganisms are coliforms (fecal and total) and aerobic mesophilic microorganisms $[25,26]$.

Opuntia ficus-indica, commonly called prickly pear, is an angiosperm and dicot plant that belongs to the Cactacea family, whose center of origin is Mexico [27, 28]. Its cultivation satisfies the food needs by consuming its stems and fruits $[29,30]$. Its fruit, called prickly pear, has been shown to be a good source of nutrients and antioxidants, and it has health benefits such as protective effects of the cardiovascular system, hepatoprotector, chemopreventive, antiproliferative, anticancer, and neuroprotective [27, 31]. However, its consumption also generates food waste, since the peel makes up $56.7 \%$ of the fruit, which represents a serious environmental problem due to the potential growth of microorganisms [32].

The objective of this work was to generate AgNPs from reducing and stabilizing agents present in the aqueous extract of the prickly peel and to verify its antibacterial activity in treated wastewater before and after the chlorination process.

\section{Materials and Methods}

2.1. Materials and Reagents. The reagents were $99 \% \mathrm{AgNO}_{3}$ (Karal), $2 \% \mathrm{HNO}_{3}$, and Silver Standard for Atomic Absorption Spectroscopy (PE Pure Atomic Spectroscopy Standard). Culture media are as follows: LB medium prepared with peptone (Bioxon), yeast extract (Bioxon), and $\mathrm{NaCl}$ (JT Baker); red phenol broth with lactose, MR-VP medium (DIBICO), Escherichia coli (EC) broth (Difco), methylene blue eosin agar (EMB), standard method agar, 2\% bright green bile broth (BRILA), SIM medium (Bioxon), and Simmons citrate agar (MCD LAB). The water samples were taken from the effluent of the water treatment plant of the Autonomous University of Aguascalientes (AUA), after the biological treatment, before and after chlorination; the water samples were treated with $10 \%$ sodium thiosulfate to stop the effect of chlorination.

2.2. Preparation of the Prickly Pear Extract. The prickly pear peel was washed with sterile distilled water, $50 \mathrm{~g}$ weighed, ground with liquid nitrogen and mixed with $250 \mathrm{ml}$ of sterile distilled water. The mixture was heated to $80^{\circ} \mathrm{C}$ in a water bath for $30 \mathrm{~min}$, and the aqueous extract was recovered by filtration with Whatman No. 1 paper.

2.3. Green Synthesis of OfAgNPs. In a $250 \mathrm{ml}$ flask, $10 \mathrm{ml}$ of the filtered extract was mixed with $90 \mathrm{ml}$ of $2 \mathrm{mM} \mathrm{AgNO}_{3}$ and incubated at room temperature, protected from light, with constant shaking at $90 \mathrm{rpm}$, until it changed color from yellow to reddish brown. Later, it was centrifuged at $12,000 \mathrm{rpm}$ for $5 \mathrm{~min}$, the supernatant was decanted, and the precipitate was washed three times with sterile distilled water and once with $96 \%$ alcohol. The OfAgNPs were dried at $37^{\circ} \mathrm{C}$ for $24 \mathrm{~h}$ and pulverized and sonicated for $20 \mathrm{~min}$ for dispersion.

\subsection{OfAgNPs Characterization}

2.4.1. Obtaining the Resonance Plasmon. The colloids obtained were scanned in a wavelength range of 300-800 nm in the Thermo scientific UV-Visible Genesis 10s UV-Vis spectrophotometer.

2.4.2. Scanning Electronic Microscopy (SEM). The dried samples were placed in the $1 \mathrm{~cm} \times 1 \mathrm{~cm}$ sticky graphite disc and were covered with the gold plating (Dentom Vacuum). A current flow was introduced at an estimated time of 80-150 s. The sample was introduced into the scanning electron microscope chamber, and the diameter of the OfAgNPs was measured from the micrographs with the Image J2 program [33]. Three hundred NPs were measured to obtain the size distribution histogram and the coefficient of variation (CV) was determined from the following formula:

$$
\mathrm{CV}=(\text { standard deviation/mean }) * 100
$$

2.4.3. Energy-Dispersive X-Ray Spectroscopy (EDXMA). The OfAgNPs solid sample was mounted in the vacuum chamber of the scanning electron microscope. The sample was observed at $12 \mathrm{~mm}$ distance between the lens and the focal plane, at an acceleration voltage of $20 \mathrm{kV}$, spot size of 42 on the SEM monitor. On the monitor of the EDS Rx analyzer, the image that appears on the screen was selected for quantitative and qualitative analysis. Four sites of interest were analyzed in a circular area of $144 \mathrm{~mm}^{2}$. Each of the four sites was analyzed at $4000 \mathrm{x}$ magnification, $200 \mathrm{~s}$ to obtain element composition. 
2.4.4. Atomic Absorption Spectroscopy. For digestion, $79.5 \mathrm{mg}$ of powder containing the OfAgNPs was dissolved with $15 \mathrm{ml}$ of $1: 1 \mathrm{HNO}_{3}$, heated to boiling, filtered through Whatman No. 1 paper, and heightened to a volume of $25 \mathrm{ml}$ with distilled $\mathrm{H}_{2} \mathrm{O}$. Samples were analyzed in a Perkin Elmer 3110 kit, and a calibration curve with 1, 2.5, and 5 ppm was made from the silver standard. An atomic absorption hollow cathode lamp was used for silver at a wavelength of $328.1 \mathrm{~nm}$.

2.4.5. Hydrodynamic Diameter and Zeta Potential. The hydrodynamic diameter of the OfAgNPs was determined with the use of the Dynamic Light Scattering (DLS) technique in a Zetasizer ZS90 (Malvern) equipment. Starting from a cumulative adjustment up to order two of the correlation function of the intensity dispersed at $90^{\circ}$, as described in the literature [34]. Zeta potential was obtained from electrophoretic mobility using the Smoluchowski model [35] available in the team's software. The analyses were performed on an OfAgNPs colloid prepared in ultrapure water (Milli-Q) at a concentration of $100 \mathrm{mg} / \mathrm{l}$. Measurements were taken in triplicate at times of $0,72,96$, and $120 \mathrm{~h}$.

\subsection{Analysis of the Antibacterial Activity of OfAgNPs in Wastewater Samples}

2.5.1. Exposure of Wastewater Samples Treated with OfAgNPs. Fifty $\mathrm{ml}$ samples of treated wastewater were collected in sterile containers. The samples were taken before and after chlorination (Figure 1). Two hundred $\mu \mathrm{l}$ of $10 \%$ sodium thiosulfate $\left(\mathrm{Na}_{2} \mathrm{~S}_{2} \mathrm{O}_{3}\right)$ was added to each of the samples.

OfAgNPs were added to $1 \mathrm{ml}$ aliquots of these water samples with a $0.5 \mathrm{mg} / \mathrm{ml}$ concentration, from a stock of $5 \mathrm{mg} / \mathrm{ml}$ prepared in phosphate buffer ( $\mathrm{pH} 7)$. To determine the minimum time of inhibition, the samples were incubated at room temperature with constant shaking and at times of $0.5,1,2,4$, and $6 \mathrm{~h}$; it was plated by means of the plate extension technique in LB medium. The shortest time in which there was an absence of colonies determined the minimum inhibition time $(0.5 \mathrm{~h})$.

OfAgNPs colloids were prepared with 0.5 and $1.0 \mathrm{mg} / \mathrm{ml}$ concentrations in a volume of $20 \mathrm{ml}$ with water samples from the treatment plant; they were exposed for about $0.5 \mathrm{~h}$ with constant agitation at $90 \mathrm{rpm}$, and then, the microbiological analysis was performed.

2.5.2. Microbiological Analysis. The microbiological analysis was performed on the water samples that had the following treatments: (1) no treatment (control), (2) chlorination, (3) $0.5 \mathrm{mg} / \mathrm{ml}$ OfAgNPs, (4) $1.0 \mathrm{mg} / \mathrm{ml}$ of OfAgNPs, (5) chlorination with $0.5 \mathrm{mg} / \mathrm{ml}$ OfAgNPs, and (6) chlorination with $1.0 \mathrm{mg} / \mathrm{ml}$ OfAgNPs.

2.5.2.1 Total and Fecal Coliforms Determination. Total and fecal coliform microorganism determination was performed by the most probable number (MPN) method, which is divided into two phases: the presumptive and the confirmatory. Serial dilutions of water samples were made from the six treatments at $10^{-1}, 10^{-2}, 10^{-3}$, and $10^{-4}$. In the presumptive phase, $1 \mathrm{ml}$ of each of the dilutions of the water samples was inoculated into the liquid phenol red broth liquid medium and incubated at $37^{\circ} \mathrm{C}$ in a period of $24-48 \mathrm{~h}$.
For the confirmatory phase of total coliforms, two roasts were taken from the positive tubes of the presumptive phase, from which they presented a change in coloration of the medium from red to yellow and the presence of gas. The BRILA broth was inoculated and incubated at $37^{\circ} \mathrm{C}$ for 24-48 h. For the confirmatory phase of fecal coliforms, two roasts were taken from the positive tubes of the confirmatory phase of total coliforms, which showed bacterial and gas growth, and the EC broth medium was inoculated and incubated at $44.5^{\circ} \mathrm{C}$ for a period of $24-48 \mathrm{~h}$. The BRILA broth cultures that showed evident bacterial growth were inoculated in the EMB differential selective solid medium from which typical colonies were selected to then perform the biochemical tests for their identification (IMViC: Indole, Mobility, Voges Proskauer, Simmons Citrate) using the SIM semisolid medium, the MR-VP liquid medium and the Simmons citrate solid medium. All tests were performed in triplicate. Total and fecal coliforms are reported as the most probable number per $100 \mathrm{ml}$ of sample (MPN/100 ml).

2.5.2.2 Aerobic Mesophilic Microorganisms Determination. The aerobic mesophilic microorganisms were counted using the plate pouring technique on the agar medium for standard methods. One $\mathrm{ml}$ of the dilutions of each water treatment in $20 \mathrm{ml}$ of agar medium for standard methods was added and incubated at $37^{\circ} \mathrm{C}$ for $24-48 \mathrm{~h}$. After that time, the count of the colonies was carried out and the log inhibition $(\log 10 \mathrm{~N} 0 / \mathrm{N})$ was calculated for each treatment; where $\mathrm{N} 0$ is the initial count, and $\mathrm{N}$ is the count after treatment [36]. The results were analyzed by means of a one-way ANOVA followed by a Tukey test $(\alpha<0.05)$. The graphs were made in the GraphPad Prism 6.0 program [37], considering the average of the repetitions \pm one standard deviation.

\section{Results and Discussion}

3.1. Green Synthesis and Characterization of OfAgNPs. The synthesis of OfAgNPs was initially verified with the change of coloration to dark brown in the colloidal solution (Figure 2(a)). This coloration change is characteristic of the AgNPs synthesis due to the reduction of silver nitrate in the presence of reducing agents from the extract of the prickly pear peel, which leads to an increase in color ranging from yellow to brown, as a result of the resonance of the superficial plasmon [38]. The color of the solution depends directly on the size and shape of the AgNPs [39]. The plasmon obtained showed the spectral characteristics of the AgNPs, with a peak in a wavelength of $435 \mathrm{~nm}$ and a width of $150 \mathrm{~nm}$ (Figure 2(b)). Those characteristics allow to infer that the size of OfAgNPs is between 60 and $80 \mathrm{~nm}$ as reported by Mulfinger et al. [40, 41]. Similar results were obtained with the extract of Chrysanthemum indicul L. with a NPs size between 37.71 and $71.99 \mathrm{~nm}$ [42] and from the blackberry with a size between 12 and $50 \mathrm{~nm}$ [43], both with a maximum length of $435 \mathrm{~nm}$. The optical properties of AgNPs result from the interaction with light, so the resonance plasmon depends on different factors such as shape, size, composition, refractive index of the metal, presence of adsorbed species, dielectric environment, electromagnetic mutual interactions, and the separation between them. These factors 


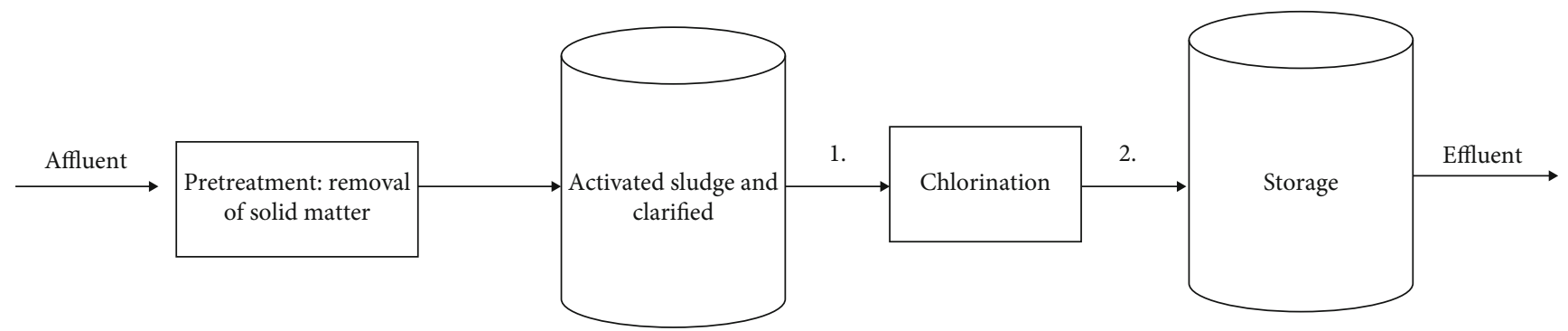

Figure 1: Water treatment plant scheme of the Autonomous University of Aguascalientes. The antimicrobial activity of the OfAgNPs was analyzed in water samples from this treatment plant taken at two points (1) before and (2) after chlorination.

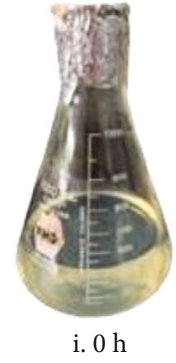

(a)

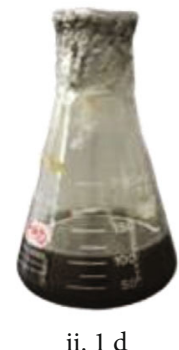

ii. $1 \mathrm{~d}$

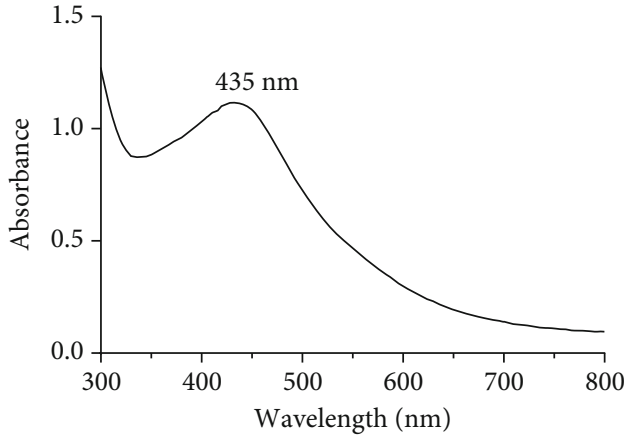

(b)

FIgure 2: Synthesis of OfAgNPs. (a) Coloration characteristic change of the OfAgNPs synthesis (i) at 0 h and (ii) day 1 of synthesis. (b) OfAgNPs resonance plasmon, absorbance scan at wavelengths of $300-800 \mathrm{~nm}$ in UV-visible spectrophotometer.

determine that the absorption peak is in the range of 393-738 nm [13, 40, 44, 45].

SEM analysis showed that OfAgNPs have a spherical shape (Figure 3(a)), being the most common form. Other researchers synthesized AgNPs with Capsicum annuum L. [7] and Syzygium aromaticum extract [46] resulting in NPs with spherical morphology. In the distribution size histogram, it was observed that the average diameter is $64.28 \pm 11.82 \mathrm{~nm}$ (Figure 3(b)), which coincides perfectly with the predictive results obtained from the resonance plasmon. AgNPs with a size of $25 \mathrm{~nm}$ were synthesized from the Boerhaavia disffusa extract [15] and $34 \mathrm{~nm}$ from Azadirachta indica [16]. The difference in size and shape between the biosynthesized AgNPs is due to temperature, $\mathrm{pH}$, synthesis time, reducing agents present in the extract, and concentration of the metal precursor [47]. The coefficient of variation was 18.39 , which proves that monodisperse nanoparticles exist in the colloid, and the OfAgNPs are mostly homogeneous in shape and size. These results are opposite to polydisperous biosynthesized NPs in the colloidal solution obtained from Albizia adiantifolia reported by Gengan et al. [48].

The hydrodynamic diameter values have little variation over time; at time 0 , it is $264 \pm 0.015 \mathrm{~nm}$, and at $120 \mathrm{~h}$, it is $220 \pm 0.018 \mathrm{~nm}$ (Figure 4(a)). These values exceed the nanometric scale and are also greater than the value obtained in the SEM measurements. The size differences between the SEM and the hydrodynamic diameter are because the SEM measures the physical size of the metallic NPs, while the DLS measures the size of the particle together with the biomolecules that are attached to the surface of the AgNPs
[49]. Similarly, the AgNPs synthesized from leaves of Brassica rapa by Narayanan and Park [50] showed a larger hydrodynamic diameter size $(39.5 \mathrm{~nm})$ than the average size obtained in TEM $(16.14 \mathrm{~nm})$. The phytochemical compounds found in the prickly pear peel extract participate as reducing agents in the synthesis and in the coating of AgNPs, which represents an advantage, since it is not necessary to add chemicals stabilizer. Alkaloids, flavones, anthracenes, terpenoids, and flavonoids present in extracts of plant stabilize and coat metallic NPs in plant biosynthesis [51]. Besides, it has been reported that aqueous extract of prickly pear peel contains phenolic acids (quercentine, kaempferol), vitamins (k1, alpha-tocopherol, beta-tocopherol), and sterols (campesterol, lanosterol and stigmasterol) [27]. These compounds could be the ones that cover the OfAgNPs. The zeta potencial values were at time 0 of $-25.1 \pm 0.03 \mathrm{mV}$ and at $120 \mathrm{~h}$ of $24.2 \pm 0.06 \mathrm{mV}$ (Figure 4(b)), indicating that OfAgNPs have a negative charge and are relatively stable over time. These results coincide with those of Sufyani et al. [18] who synthesized AgNPs from Lavandula chrysophyla extract with negative charge and greater stability, having a zeta potential value of $-14.3 \mathrm{mV}$, but not with those synthesized from the Olea chrysophylla extract with a low stability according to the zeta potential value of -0.877 . The negative charge and the stability are provided by the molecules integrated into the surface during the synthesis process, which generate electrostatic or steric repulsion, giving them stability, avoiding agglomeration and therefore precipitation in solution [52].

The element analysis by EDXMA from OfAgNPs showed that the silver was found in the highest percentage with 


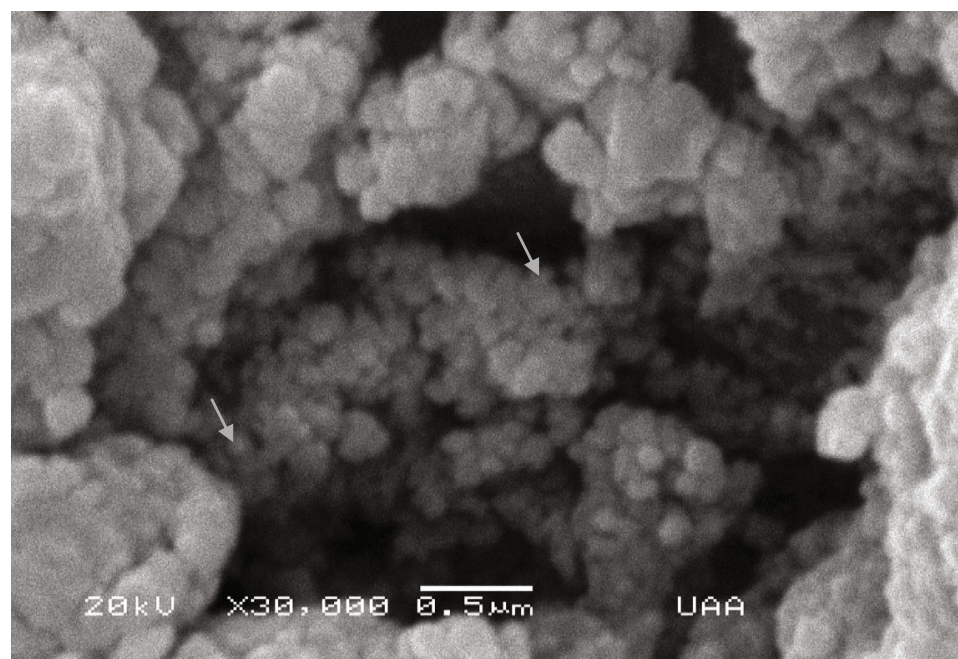

(a)

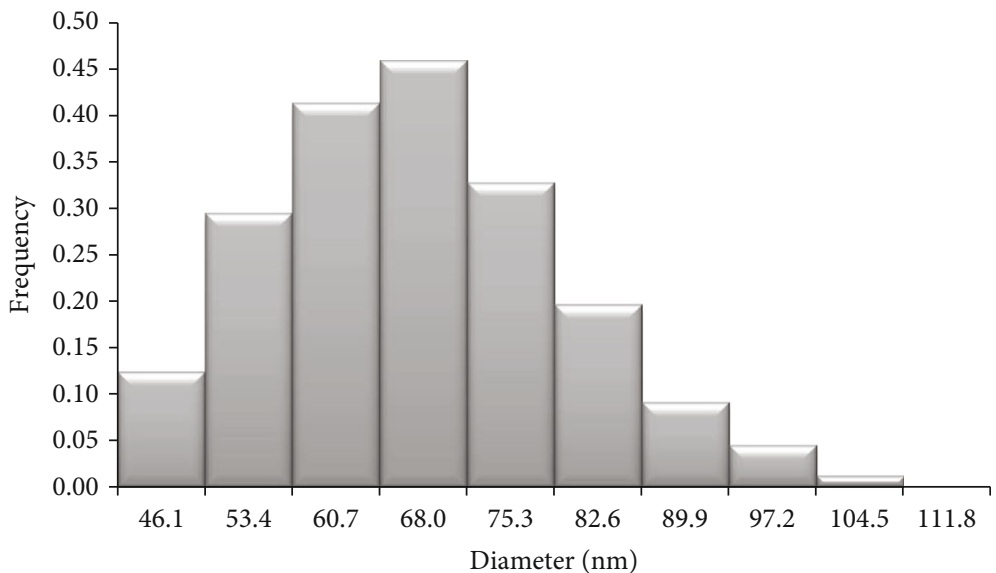

(b)

FIgure 3: Morphology and diameter of OfAgNPs. (a) SEM micrography, the OfAgNPs have a spherical morphology and are agglomerated due to the preparation of the sample. (b) Histogram of size distributions of the OfAgNPs, the diameter is distributed between 46.1 and $104.5 \mathrm{~nm}$, with an average of $64.28 \pm 11.82 \mathrm{~nm}(n=300)$.

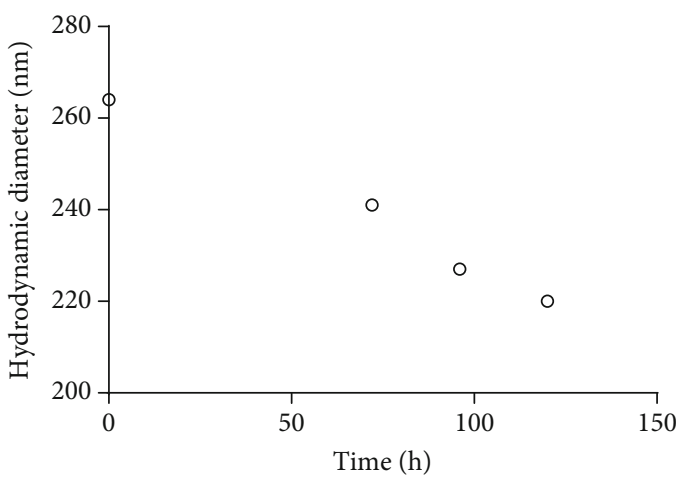

(a)

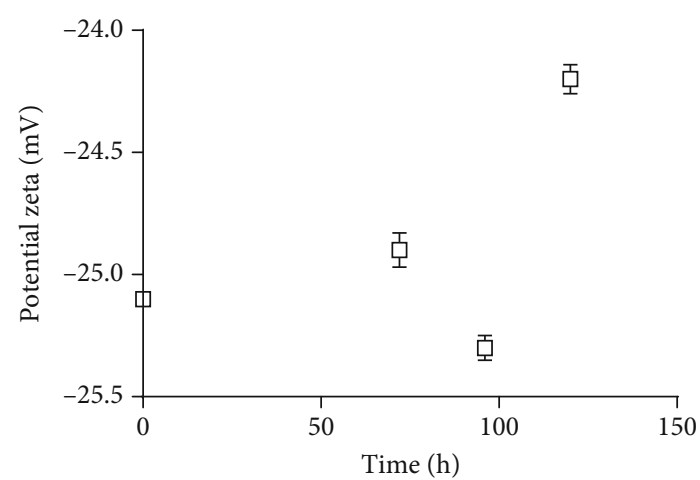

(b)

FIgURE 4: Graphs of the behavior of the hydrodynamic diameter and zeta potential of OfAgNPs over time in ultrapure water at room temperature. (a) Hydrodynamic diameter, the average value of the hydrodynamic diameter is $238 \pm 0.015 \mathrm{~nm}$. (b) Zeta potential, the values indicate that the OfAgNPs are relatively stable and that they have a negative charge with an average value of $-24.87 \pm 0.05 \mathrm{mV}$. The measurements were made in triplicate, and the average with a standard deviation is shown. 

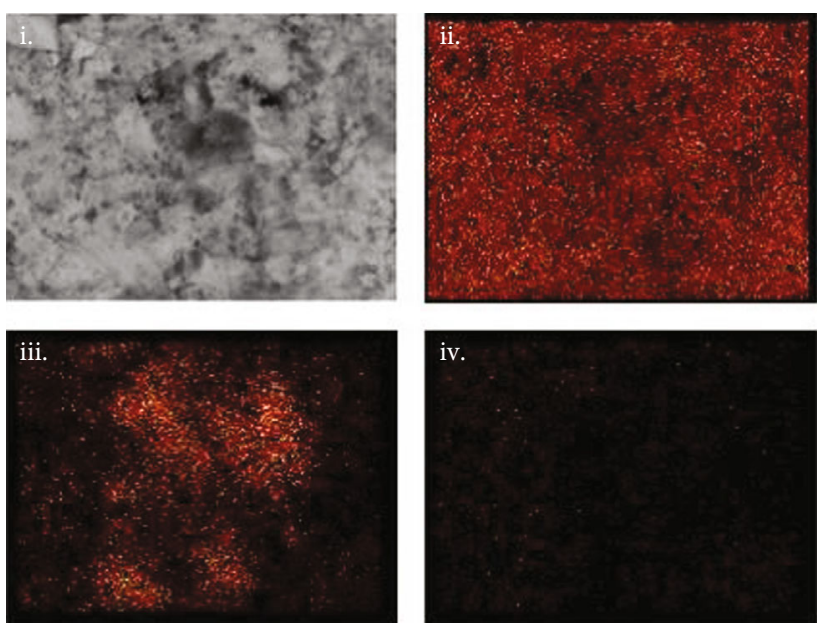

(a)

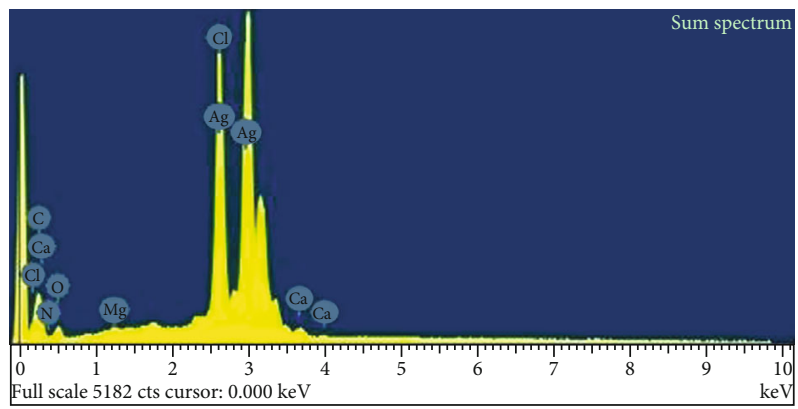

(c)

\begin{tabular}{cccccccc}
\hline Element & $\begin{array}{c}\text { Carbon } \\
(\mathrm{C})\end{array}$ & $\begin{array}{c}\text { Nitrogen } \\
(\mathrm{N})\end{array}$ & $\begin{array}{c}\text { Oxygen } \\
(\mathrm{O})\end{array}$ & $\begin{array}{c}\text { Magnesium } \\
(\mathrm{Mg})\end{array}$ & $\begin{array}{c}\text { Chlorine } \\
(\mathrm{Cl})\end{array}$ & $\begin{array}{c}\text { Calcium } \\
(\mathrm{Ca})\end{array}$ & $\begin{array}{c}\text { Silver } \\
(\mathrm{Ag})\end{array}$ \\
\hline Weight $(\%)$ & 15.40 & 1.17 & 6.59 & 0.29 & 14.68 & 0.58 & 61.29 \\
\hline
\end{tabular}

(b)

FIgure 5: OfAgNPs composition elements. (a) EDXMA micrographs: (i) micrograph of the OfAgNPs, (ii) silver distribution, (iii) carbon distribution, and (iv) oxygen distribution. The red spots indicate the distribution of some of the elements that make up the OfAgNPs. (b) Quantitative estimation of elements by EDXMA. (c) EDXMA spectrum of OfAgNPs.

TABLE 1: Total and fecal coliforms in water samples from the AUA treatment plant, treated and untreated with different OfAgNPs concentrations.

\begin{tabular}{lccc}
\hline Tertiary treatment & $\begin{array}{c}\text { Total coliforms } \\
(\mathrm{MPN} / 100 \mathrm{ml})\end{array}$ & $\begin{array}{c}\text { Faecal coliforms } \\
(\mathrm{MPN} / 100 \mathrm{ml})\end{array}$ & Identified species \\
\hline No treatment & 430 & 150 & $\begin{array}{c}\text { E. coli var 1, E. aerogenes var 1, C. freundii var 2, } \\
\text { E. coli atypical }\end{array}$ \\
Chlorination & 91 & 0.03 & E. coli var 1 \\
$0.5 \mathrm{mg} / \mathrm{ml}$ of OfAgNPs $\left(0.120 \mathrm{mg} \mathrm{of} \mathrm{Ag}^{+}\right)$ & 0.03 & 0.03 & None \\
$1.0 \mathrm{mg} / \mathrm{ml}$ de OfAgNPs $\left(0.241 \mathrm{mg} \mathrm{de} \mathrm{Ag}^{+}\right)$ & 0.03 & 0.03 & None \\
Chlorination $+0.5 \mathrm{mg} / \mathrm{ml}$ of OfAgNPs & 0.03 & 0.03 & None \\
Chlorination $+1.0 \mathrm{mg} / \mathrm{ml}$ of OfAgNPs & 0.03 & 0.03 & None \\
\hline
\end{tabular}

MPN: most probably number.

$61.29 \%$. The presence of other elements was also identified such as carbon $(15.40 \%)$, nitrogen $(1.17 \%)$, oxygen $(6.59 \%)$, magnesium $(0.29 \%)$, chlorine $(14.68 \%)$, and calcium $(0.58 \%)$ (Figures 5(a)-5(c)). Calcium and magnesium are elements present in the prickly pear peel [29]; therefore, it was expected that they form part of the synthesized NPs. Dhand et al. [53] biosynthesized AgNPs from the Coffea arabica seeds with silver as the main element. Arokiyaraj et al. [42] obtained AgNPs using extract of Chrysanthemum indicum L. made up for silver, carbon, oxygen, and chlorine. These elements are part of the covering of the AgNPs. The distribu- tion of the elements in the sample shows that the highest percentage is silver (Figure 5(a)). By atomic absorption spectroscopy, the silver yield was calculated, where it was observed that, for $100 \mathrm{~g}$ of synthesized material, there is $24.15 \mathrm{~g}$ of silver, leading to a percentage of $24.15 \%$. This proves that the rest of the weight of the sample are phytochemical compounds from the extract.

3.2. Antibacterial Activity Analysis of OfAgNPs. Coliform bacteria were identified in the nonchlorinated treated wastewater sample: E. coli var 1, E. aerogenes var 1, C. freundii var 
2, and an atypical E. coli. These bacteria generate diseases in humans: $E$. coli causes diarrhea, intestinal and urinary tract infections, and meningitis [54]; E. aerogenes causes infections in the urinary tract, gastrointestinal, and respiratory system [55], and C. freundii causes sepsis and meningitis in the neonatal period [56]. Furthermore, these microorganisms are considered indicators of the presence of pathogenic organisms [26].

In the microbiological analysis of chlorinated water from the treatment plant, an elimination of $79 \%$ of the total coliform bacteria was observed. The only coliform microorganism detected was E. coli var 1, indicating the presence of fecal contamination (Table 1). The water samples, both those that went through a chlorination process and those that did not, were treated with 0.5 and $1.0 \mathrm{mg} / \mathrm{ml}$ OfAgNPs for $0.5 \mathrm{~h}$. These conditions were determined considering the minimum inhibition time previously calculated. A value of $0.03 \mathrm{MPN} / 100 \mathrm{ml}$ was obtained for both total and fecal coliform (Table 1), indicating the absence of these bacteria, while in the samples that only were subjected to the chlorination process, a total coliform count of $91 \mathrm{MPN} / 100 \mathrm{ml}$ was obtained, which shows their presence. From this parameter, it would allow the reuse of the residual water, since the Mexican standard indicates that in order to use it in public service with direct contact, a maximum allowable limit of $240 \mathrm{MPN} / 100 \mathrm{ml}$ is required, and for public services with indirect or occasionally contact, a maximum limit of 1,000 MPN/100 ml is required [20].

According to the logarithmic inactivation results, the treatments that involve exposure to the OfAgNPs are significantly more effective than the chlorination in the inhibition of aerobic mesophilic microorganisms. The chlorination process caused $90 \%$ inhibition of aerobic mesophyll bacteria, while OfAgNPs treatments showed an inhibition greater than 99\% (Figure 6). Furthermore, in these organisms, no significant differences were observed between the two concentrations of OfAgNPs evaluated in both water samples (chlorine-free and chlorinated) (Figure 6). These results showed that a treatment with $0.5 \mathrm{mg} / \mathrm{ml}$ of OfAgNPs for $0.5 \mathrm{~h}$ is sufficient to eliminate both coliforms and aerobic mesophyll microorganisms, proving their action against Gram (-) bacteria. It is important to highlight the availability of $\mathrm{Ag}^{+}$in the synthesized material, because, according to the analysis of atomic absorption spectroscopy, it is equivalent to $0.120 \mathrm{mg}$ and $0.241 \mathrm{mg}$ of $\mathrm{Ag}^{+}$, in the samples of 0.5 and $1 \mathrm{mg} / \mathrm{ml}$ of $O f A g N P s$, respectively.

There is a direct relationship between the action mechanisms of AgNPs against bacteria and their characteristics, such as shape, size, surface area, agglomeration state, and surface charge [57]. The AgNPs cause cell damage because they interact directly with the membrane, and because silver ions released from AgNPs generate reactive oxygen species (ROS) which interact and damage biomolecules such as lipids, DNA, and proteins $[57,58]$. Currently, biosynthesized AgNPs are recognized both for their activity against Gram $(+)$ and Gram (-) bacteria, as well as for their low toxicity in plants and animals [58-60]. Due to these observations, the use of OfAgNPs as an alternative to chlorination used as a tertiary process in wastewater treatment plants is proposed.

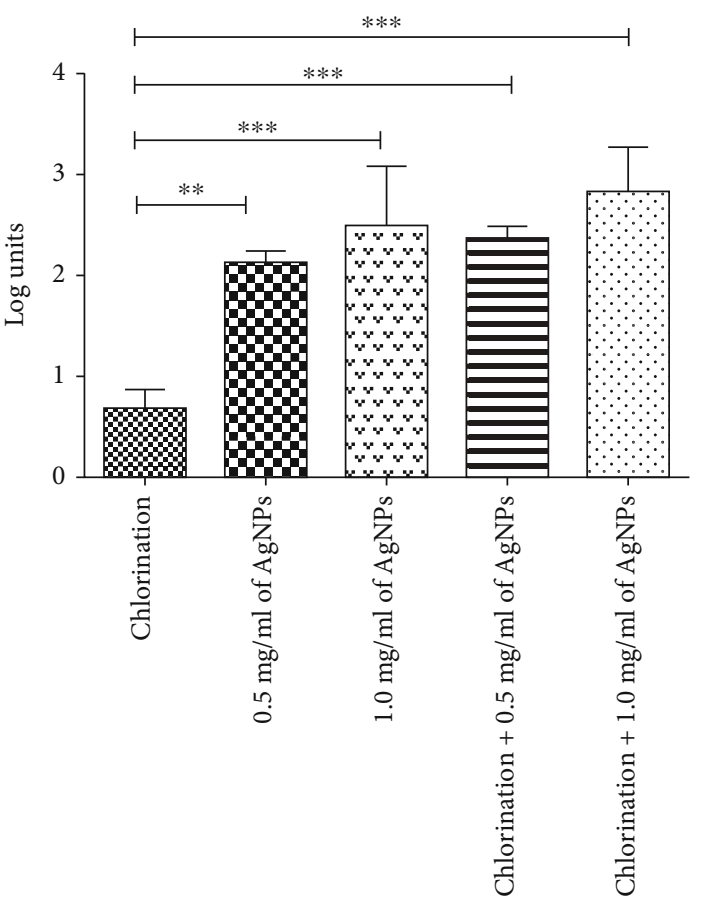

FIGURE 6: Bacterial inactivation of aerobic mesophilic microorganisms. The water samples were exposed to the OfAgNPs for $0.5 \mathrm{~h}$. The initial count of microorganisms was $1.70 \times 10^{4} \mathrm{CFU} / \mathrm{ml}$. The test was performed in triplicate, and the mean \pm one standard deviation was plotted. Variability between treatments was determined with a onefactor ANOVA test, and a Tukey test $(\alpha<0.05)$ was performed to assess the significance of the observed differences.

\section{Conclusions}

AgNPs were biosynthetized from aqueous extract of prickly pear fruit peel and were designated as OfAgNPs. OfAgNPs had a spherical, negatively charged morphology and were relatively stable. In addition, the growth of coliform bacteria $E$. coli var 1, E. aerogenes var 1, C. freundii var 2, an atypical $E$. coli, and aerobic mesophyll microorganisms present in treated wastewater was inhibited with $0.5 \mathrm{mg} / \mathrm{ml}$ OfAgNPs for $0.5 \mathrm{~h}$. OfAgNPs presented an antimicrobial activity higher than chlorination, so they could be used as a tertiary process for wastewater treatment.

\section{Data Availability}

The data used to support the findings of this study are included within the article.

\section{Conflicts of Interest}

We declare that we do not have conflicts of interest.

\section{Acknowledgments}

The authors would like to thank the National Science and Technology Council (CONACYT) for the scholarship (766020) and Autonomous University of Aguascalientes for 
the investigation support; to Dr. Catalina Haro Pérez from the Complex Systems Laboratory of the Autonomous Metropolitan University, Azcapotzalco Unit; to M.C. Norma Adela Carrasco Esparza from the Microbiology Laboratory; to Dr. Ana Carbajal Hernández and Dr. Roberto Rico Martínez from the Aquatic Toxicology laboratory; and to M.C. José Luis Moreno Hernández-Duque of the Instrumental Analysis Laboratory of the Autonomous University of Aguascalientes.

\section{References}

[1] N. A. Singh, "Nanotechnology definitions, research, industry and property rights," Nanoscience in Food and Agriculture, vol. 1, pp. 43-64, 2016.

[2] M. Boholm and R. Arvidsson, "A definition framework for the terms nanomaterial and nanoparticle," NanoEthics, vol. 10, no. 1, pp. 25-40, 2016.

[3] W. R. Li, X. B. Xie, Q. S. Shi, H. Y. Zeng, Y. S. OU-Yang, and Y. B. Chen, "Antibacterial activity and mechanism of silver nanoparticles on Escherichia coli," Applied Microbiology and Biotechnology, vol. 85, no. 4, pp. 1115-1122, 2010.

[4] V. Gopinath and P. Velusamy, "Extracellular biosynthesis of silver nanoparticles using Bacillus sp. GP-23 and evaluation of their antifungal activity towards Fusarium oxysporum," Spectrochimica Acta Part A: Molecular and Biomolecular Spectroscopy, vol. 106, pp. 170-174, 2013.

[5] S. Galdiero, M. Rai, A. Gade et al., "Antiviral activity of mycosynthesized silver nanoparticles against herpes simplex virus and human parainfluenza virus type 3," International Journal of Nanomedicine, vol. 8, p. 4303, 2013.

[6] K. Vasanth, K. Ilango, R. MohanKumar, A. Agrawal, and G. P. Dubey, "Anticancer activity of Moringa oleifera mediated silver nanoparticles on human cervical carcinoma cells by apoptosis induction," Colloids and Surfaces B: Biointerfaces, vol. 117, pp. 354-359, 2014.

[7] S. Li, Y. Shen, A. Xie et al., "Green synthesis of silver nanoparticles using Capsicum annuum L. extract," Green Chemistry, vol. 9, no. 8, pp. 852-858, 2007.

[8] F. Viñes, "Simulating heterogeneous catalysis on metallic nanoparticles: from under-coordinated sites to extended facets," Frontiers of Nanoscience, vol. 12, no. 8, pp. 101-128, 2018.

[9] Q. Zhang, N. Li, J. Goebl, Z. Lu, and Y. Yin, "A Systematic Study of the Synthesis of Silver Nanoplates: Is Citrate a "Magic" Reagent?," Journal of the American Chemical Society, vol. 133, no. 46, pp. 18931-18939, 2011.

[10] S. Iravani, H. Korbekandi, S. V. Mirmohammadi, and B. Zolfaghari, "Synthesis of silver nanoparticles: chemical, physical and biological methods," Research in Pharmaceutical Sciences, vol. 9, no. 6, pp. 385-406, 2014.

[11] A. A. Hebeish, M. H. El-Rafie, F. A. Abdel-Mohdy, E. S. AbdelHalim, and H. E. Emam, "Carboxymethyl cellulose for green synthesis and stabilization of silver nanoparticles," Carbohydrate Polymers, vol. 82, no. 3, pp. 933-941, 2010.

[12] S. Iravani, "Green synthesis of metal nanoparticles using plants," Green Chemistry, vol. 13, no. 10, pp. 2638-2650, 2011.

[13] L. Wei, J. Lu, H. Xu, A. Patel, Z. Chen, and G. Chen, "Silver nanoparticles: synthesis, properties, and therapeutic applications," Drug Discovery Today, vol. 20, no. 5, pp. 595-601, 2015.
[14] M. Gómez-Garzón, "Nanomaterials, nanoparticles and green synthesis," Repertoire of Medicine and Surgery Magazine, vol. 27, no. 2, 2018.

[15] S. Ahmed, M. Saifullah, B. Ahmad, L. Swami, and S. Ikram, "Green synthesis of silver nanoparticles using Azadirachta indicaaqueous leaf extract," Journal of Radiation Research and Applied Sciences, vol. 9, no. 1, pp. 1-7, 2019.

[16] P. P. N. Vijay Kumar, S. V. N. Pammi, P. Kollu, K. V. V. Satyanarayana, and U. Shameem, "Green synthesis and characterization of silver nanoparticles using Boerhaavia diffusa plant extract and their anti bacterial activity," Industrial Crops and Products, vol. 52, pp. 562-566, 2014.

[17] M. F. Zayed, W. H. Eisa, and A. A. Shabaka, "Malva parviflora extract assisted green synthesis of silver nanoparticles," Spectrochimica Acta Part A: Molecular and Biomolecular Spectroscopy, vol. 98, pp. 423-428, 2012.

[18] N. M. al Sufyani, N. A. Hussien, and Y. M. Hawsawi, "Characterization and Anticancer Potential of Silver Nanoparticles Biosynthesized from Olea chrysophylla and Lavandula dentata Leaf Extracts on HCT116 Colon Cancer Cells," Journal of Nanomaterials, vol. 2019, Article ID 7361695, 9 pages, 2019.

[19] M. Kgatshe, O. S. Aremu, L. Katata-Seru, and R. Gopane, "Characterization and Antibacterial Activity of Biosynthesized Silver Nanoparticles Using the Ethanolic Extract of Pelargonium sidoides DC," Journal of Nanomaterials, vol. 2019, Article ID 3501234, 10 pages, 2019.

[20] Mexican Official Standard NOM-003-ECOL-1997Federation's Official Journal. Mexico City, Mexico, 1998.

[21] G. P. Winward, L. M. Avery, T. Stephenson, and B. Jefferson, "Chlorine disinfection of grey water for reuse: effect of organics and particles," Water Research, vol. 42, no. 1-2, pp. 483-491, 2008.

[22] G. Moeller and A. Tomasi, "Microbiology of activated sludge," Proceedings of the international course on integrated wastewater treatment systems and their reuse for a sustainable environment, Mexican Institute of Water Technology (IMTA), Bogotá, 2004.

[23] J. B. da Costa, S. Rodgher, L. A. Daniel, and E. L. G. Espíndola, "Toxicity on aquatic organisms exposed to secondary effluent disinfected with chlorine, peracetic acid, ozone and UV radiation," Ecotoxicology, vol. 23, no. 9, pp. 1803-1813, 2014.

[24] National Research Council, Indicators for waterborne pathogens, National Academies Press, 2004.

[25] S. Rós-Tobón, R. M. Agudelo-Cadavid, and L. A. GutiérrezBuiles, "Pathogens and microbiological indicators of water quality for human consumption," National School of Public Health Magazine, vol. 35, no. 2, pp. 236-247, 2017.

[26] P. Tallon, B. Magajna, C. Lofranco, and K. T. Leung, "Microbial indicators of faecal contamination in water: a current perspective," Water, Air, and Soil Pollution, vol. 166, no. 1-4, pp. 139-166, 2005.

[27] K. el-Mostafa, Y. el Kharrassi, A. Badreddine et al., "Nopal cactus (Opuntia ficus-indica) as a source of bioactive compounds for nutrition, health and disease," Molecules, vol. 19, no. 9, pp. 14879-14901, 2014.

[28] X. Aparicio-Fernández, S. Loza-Cornejo, M. G. Torres-Bernal, N. J. Velázquez Placencia, and H. J. Arreola Nava, "Physicochemical characteristics of fruits of wild Opuntia varieties from two semi-arid regions of Jalisco, Mexico," Polibotánica, vol. 43, pp. 219-244, 2017.

[29] G. A. Becerril and C. B. P. Valdivia, "Physiological alterations caused by drought in prickly pear (Opuntia ficus-indica)," 
Mexican Plant Technology Magazine, vol. 29, no. 3, pp. 231237, 2006.

[30] P. Cerezal and G. Duarte, "Sensory influence of chemical additives on prickly pears (Opuntia ficus-indica (L.) Miller) peeled in syrup preserved by combined methods," Journal of the Professional Association for Cactus Development, vol. 6, pp. 102119, 2004.

[31] M. A. Livrea and L. Tesoriere, "Health benefits and bioactive components of the fruits from Opuntia ficus-indica L. Mill," Journal of the Professional Association for cactus Development, vol. 8, no. 1, pp. 73-90, 2006.

[32] W. Russ and R. Meyer-Pittroff, "Utilizing waste products from the food production and processing industries," Critical Reviews in Food Science and Nutrition, vol. 44, no. 1, pp. 5762, 2004

[33] C. T. Rueden, J. Schindelin, M. C. Hiner et al., "ImageJ2: ImageJ for the next generation of scientific image data," BMC Bioinformatics, vol. 18, no. 1, p. 529, 2017.

[34] B. J. Berne and R. Pecora, Dynamic light scattering with applications to chemistry, biology and physics, Dover Publications, 2000.

[35] A. V. Delgado, F. Gonzalez-Caballero, R. J. Hunter, L. K. Koopal, and J. Lyklema, "Measurement and interpretation of electrokinetic phenomena (IUPAC technical report)," Pure and Applied Chemistry, vol. 77, no. 10, pp. 1753-1805, 2005.

[36] C. Garcidueñas-Piña, I. E. Medina-Ramírez, P. Guzmán, R. Rico-Martínez, J. F. Morales-Domínguez, and I. RubioFranchini, "Evaluation of the antimicrobial activity of nanostructured materials of titanium dioxide doped with silver and/or copper and their effects onArabidopsis thaliana," International Journal of Photoenergy, vol. 2016, Article ID 8060847, 14 pages, 2016.

[37] “One-way ANOVA followed by Tukey's multiple comparisons test was performed using Graph Pad Prism version 7.00 for Windows," Graph Pad Software, La Jolla, CA, USA, http:// www.graphpad.com/.

[38] G. Suresh, P. H. Gunasekar, D. Kokila et al., "Green synthesis of silver nanoparticles using Delphinium denudatum root extract exhibits antibacterial and mosquito larvicidal activities," Spectrochimica Acta Part A: Molecular and Biomolecular Spectroscopy, vol. 127, pp. 61-66, 2014.

[39] S. J. Oldenburg, Silver nanoparticles: properties and applications, Sigma-Aldrich Co., 2014.

[40] A. Chhatre, P. Solasa, S. Sakle, R. Thaokar, and A. Mehra, "Color and surface plasmon effects in nanoparticle systems: case of silver nanoparticles prepared by microemulsion route," Colloids and Surfaces A: Physicochemical and Engineering Aspects, vol. 404, pp. 83-92, 2012.

[41] L. Mulfinger, S. D. Solomon, M. Bahadory, A. V. Jeyarajasingam, S. A. Rutkowsky, and C. Boritz, "Synthesis and study of silver nanoparticles," Journal of Chemical Education, vol. 84, no. 2, p. 322, 2007.

[42] S. Arokiyaraj, M. V. Arasu, S. Vincent et al., "Rapid green synthesis of silver nanoparticles from Chrysanthemum indicum $\mathrm{L}$ and its antibacterial and cytotoxic effects: an in vitro study," International Journal of Nanomedicine, vol. 9, p. 379, 2014.

[43] B. Kumar, K. Smita, L. Cumbal, and A. Debut, "Green synthesis of silver nanoparticles using Andean blackberry fruit extract," Saudi Journal of Biological Sciences, vol. 24, no. 1, pp. $45-50,2017$.
[44] J. Ren and R. D. Tilley, "Preparation, self-assembly, and mechanistic study of highly monodispersed nanocubes," Journal of the American Chemical Society, vol. 129, no. 11, pp. 32873291, 2007.

[45] T. Huang and X. H. N. Xu, "Synthesis and characterization of tunable rainbow colored colloidal silver nanoparticles using single-nanoparticle plasmonic microscopy and spectroscopy," Journal of Materials Chemistry, vol. 20, no. 44, pp. 9867-9876, 2010.

[46] K. Venugopal, H. A. Rather, K. Rajagopal et al., "Synthesis of silver nanoparticles (Ag NPs) for anticancer activities (MCF 7 breast and A549 lung cell lines) of the crude extract of Syzygium aromaticum," Journal of Photochemistry and Photobiology B: Biology, vol. 167, pp. 282-289, 2017.

[47] M. Shah, D. Fawcett, S. Sharma, S. K. Tripathy, and G. E. J. Poinern, "Green synthesis of metallic nanoparticles via biological entities," Materials, vol. 8, no. 11, pp. 7278-7308, 2015.

[48] R. M. Gengan, K. Anand, A. Phulukdaree, and A. Chuturgoon, "A549 lung cell line activity of biosynthesized silver nanoparticles using Albizia adianthifolia leaf," Colloids and Surfaces B: Biointerfaces, vol. 105, pp. 87-91, 2013.

[49] E. Bernardo-Mazariegos, B. Valdez-Salas, D. González-Mendoza et al., "Silver nanoparticles from Justicia spicigera and their antimicrobial potentialities in the biocontrol of foodborne bacteria and phytopathogenic fungi," Revista Argentina de Microbiologia, vol. 51, no. 2, pp. 103-109, 2019.

[50] K. B. Narayanan and H. H. Park, "Antifungal activity of silver nanoparticles synthesized using turnip leaf extract (Brassica rapa L.) against wood rotting pathogens," European Journal of Plant Pathology, vol. 140, no. 2, pp. 185-192, 2014.

[51] K. B. Narayanan and N. Sakthivel, "Phytosynthesis of gold nanoparticles using leaf extract of Coleus amboinicus Lour," Materials Characterization, vol. 61, no. 11, pp. 1232-1238, 2010.

[52] S. H. Lee and B. H. Jun, "Silver nanoparticles: synthesis and application for nanomedicine," International Journal of Molecular Sciences, vol. 20, no. 4, p. 865, 2019.

[53] V. Dhand, L. Soumya, S. Bharadwaj, S. Chakra, D. Bhatt, and B. Sreedhar, "Green synthesis of silver nanoparticles using Coffea arabica seed extract and its antibacterial activity," Materials Science and Engineering: C, vol. 58, pp. 36-43, 2016.

[54] J. B. Kaper, J. P. Nataro, and H. L. Mobley, "Pathogenic Escherichia coli," Nature Reviews Microbiology, vol. 2, no. 2, pp. 123-140, 2004

[55] A. Davin-Regli and J. M. Pagès, "Enterobacter aerogenes and Enterobacter cloacae; versatile bacterial pathogens confronting antibiotic treatment," Frontiers in Microbiology, vol. 6, 2015.

[56] T. I. Doran, "The role of Citrobacter in clinical disease of Children: Review," Clinical Infectious Diseases, vol. 28, no. 2, pp. 384-394, 1999.

[57] Y. N. Slavin, J. Asnis, U. O. Häfeli, and H. Bach, "Metal nanoparticles: understanding the mechanisms behind antibacterial activity," Journal of Nanobiotechnology, vol. 15, no. 1, p. 65, 2017.

[58] S. Some, I. Kumar Sen, A. Mandal et al., "Biosynthesis of silver nanoparticles and their versatile antimicrobial properties," Materials Research Express, vol. 6, no. 1, article 012001, 2019. 
[59] E. Pazos-Ortiz, J. H. Roque-Ruiz, E. A. Hinojos-Márquez et al., "Dose-Dependent Antimicrobial Activity of Silver Nanoparticles on Polycaprolactone Fibers against Gram-Positive and Gram-Negative Bacteria," Journal of Nanomaterials, vol. 2017, Article ID 4752314, 9 pages, 2017.

[60] P. Rauwel, S. Küünal, S. Ferdov, and E. Rauwel, "A review on the green synthesis of silver nanoparticles and their morphologies studied via TEM," Advances in Materials Science and Engineering, vol. 2015, Article ID 682749, 9 pages, 2015. 